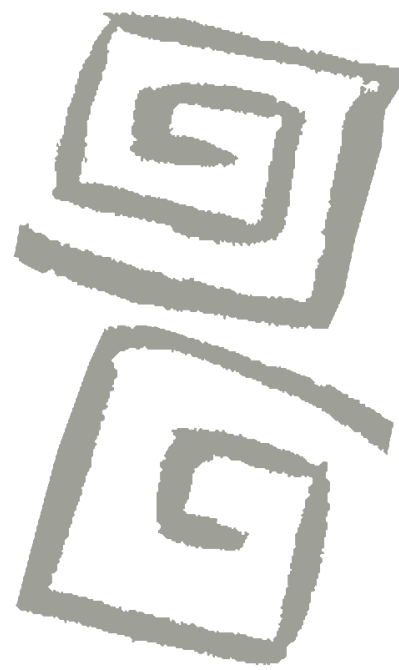

\title{
Performatividad del género, medicalización y salud en mujeres transexuales en Ciudad de México
}

\author{
Gender performativity, medicalization and health \\ in transsexual women in Mexico City
}

José Arturo Granados Cosme'; Pedro Alberto Hernández Ramírez²; Omar Alejandro Olvera Muñoz ${ }^{3}$

'Doctor en Antropología. Profesor Investigador, Universidad Autónoma Metropolitana, México. $凶$ (iD)

${ }^{2}$ Maestro en Medicina Social. Consejo Nacional para Prevenir la Discriminación, México. $\Delta$ iD

${ }^{3}$ Especialista en Medicina Social. Profesor,

Universidad Milenium

México. $₫$ iD
RESUMEN La Organización Mundial para la Salud y la American Psychological Association consideran que la transexualidad es una patología y plantean la adecuación sexogenérica para el ajuste biopsíquico de las personas trans. Mediante el análisis discursivo de la experiencia, en este estudio se describen los procesos de medicalización y performatividad del género en su relación con la salud de un grupo de mujeres trans de la Ciudad de México, para lo cual se desarrolló un estudio cualitativo en el que se realizaron, en el año 2015, diez entrevistas semiestructuradas. Como parte de la medicalización, la patologización de la transexualidad generó sufrimiento psíquico; por su parte, la adecuación sexogenérica también implicó riesgos adicionales. Se puede concluir que, en las mujeres trans, la violencia y la exclusión resultan las principales experiencias que explican los problemas de salud más relevantes por lo que se sugiere disminuir la discriminación, así como avanzar en intervenciones médicas más seguras.

PALABRAS CLAVES Transexualidad; Género; Discriminación; México.

\begin{abstract}
The World Health Organization and the American Psychological Association consider transsexuality a pathology and suggest sex-gender reassignment for the biopsychic adjustment of trans people. Through the discursive analysis of experience, this study describes the processes of medicalization and gender performativity in relation to the health of a group of trans women from Mexico City. For this purpose, a qualitative study was conducted in which 10 semi-structured interviews were carried out in 2015 . As part of medicalization, the pathologization of transsexuality generated psychic suffering; on the other hand, sex-gender reassignment also entailed additional risks. It is possible to conclude that in trans women, violence and exclusion constitute the primary experiences explaining their foremost health problems. Therefore, it is suggested that it is necessary for discrimination be reduced and for advancements to be made in safer medical interventions.
\end{abstract}

KEY WORDS Transsexualism; Gender; Discrimination; Mexico.

KEY WORDS Transsexualism; Gender; Discrimination; Mexico. 


\section{INTRODUCCIÓN}

En México, las personas transexuales (trans) son altamente discriminadas y mencionan a los servicios médicos como una de las instancias en las que con frecuencia perciben actitudes discriminatorias ${ }^{(1)}$. En Argentina, se reportan prácticas similares ejercidas por médicos, enfermeras, psicólogos y personal administrativo $^{(2)}$. El Trans Murder Monitoring ${ }^{(3)}$ reportó 295 homicidios a personas trans, informados en 33 países entre el 1 de octubre de 2015 y 30 de septiembre de 2016, la mayoría de los cuales corresponden a Brasil con 123 casos y, en segundo lugar, a México con 52 casos, país que tiene la cuarta tasa más alta (2,21 por millón de habitantes) de América ${ }^{(3)}$.

La medicina sigue considerando la transexualidad como una patología ${ }^{(4,5)}$ y plantea una serie de intervenciones para ajustar la corporalidad a la identidad de género que se denomina readecuación sexogenérica. La Clínica Especializada Condesa es la única instancia pública que ofrece estos servicios, forma parte de la Secretaría de Salud de la Ciudad de México, es una acción gubernamental sin precedentes en el país y forma parte de recientes reivindicaciones a los derechos de lesbianas, gays, bisexuales, transexuales, travestis, transgénero e intersexuales (LGBTTTI).

Entre los principales problemas de salud de la población trans se han identificado altos niveles de exposición a violencia verbal, emocional y física, incluyendo el homicidio $^{(6)}$. Diversos estudios documentan cómo influye el rechazo social en la salud de $\operatorname{LGBTTTI}(7,8,9,10)$, otros analizan el papel que la medicina científica ha tenido en la patologización de prácticas no heterosexuales ${ }^{(11,12)}$, planteando una relación entre esta, el rechazo social y la estigmatización ${ }^{(13,14)}$. Otros análisis desarrollan el carácter de construcción social del género ${ }^{(15,16)}$ y la imposición de un esquema heterosexual que determina las relaciones sociales, la identidad y la subjetividad ${ }^{(17)}$. En ese sentido, la identidad trans resulta paradigmática en una cultura binaria del género y su análisis es susceptible de aportar conocimiento sobre la relación entre sexualidad y salud, para lo cual se requiere de un abordaje "des-exotizante" ${ }^{\text {"(18) }}$ y desprejuiciado de esta población. En este caso, se particulariza en mujeres transexuales, considerándolas como aquellas personas a quienes al nacer les fue asignado el sexo de varón por mostrar genitales externos del sexo masculino, pero que desde la niñez autodefinen su identidad sexogenérica como mujeres.

Este trabajo forma parte de un proyecto de investigación del que se reportaron resultados parciales sobre el proceso de medicalización en nueve informantes ${ }^{(19)}$, en el presente texto se presentan los resultados finales en los que el análisis se amplía con las nociones de cuerpo y performatividad de género; adicionalmente, se identifican riesgos y daños a la salud, y se documenta su asociación con la experiencia de la violencia en diez informantes.

Para el abordaje de este problema, se integró un marco teórico conformado por un conjunto de conceptos básicos y generales que permitieron una mirada crítica en la lectura de las narrativas obtenidas. El cuerpo puede ser objeto y sujeto, "capaz de ver y sufrir"(20), es una experiencia, un mundo de significaciones vividas, "el cuerpo... es un producto social"(21). El agente comprende el mundo a través del cuerpo porque los principios con que lo percibe son producto de las estructuras sociales en que actúa, el agente tiene capacidad de crear la realidad social al estar dotados de habitus que se han incorporado por medio de experiencias ${ }^{(21)}$. Esto significa que el orden social se inscribe en los cuerpos mediante transacciones afectivas con el entorno. El género es una estructura social que se incorpora en el cuerpo mediante el aprendizaje de la masculinidad y la feminidad, e inscribe la diferencia entre los sexos en el cuerpo a través de modos diferenciales de subjetividad y conducta. El cuerpo, en tanto espacio de incorporación del orden social, es atravesado por estructuras como el sexo, el género y la sexualidad.

El género se ha entendido como el conjunto de ideas socialmente construidas a partir de la diferencia sexual entre varones y mujeres, atribuyéndoles características 
"femeninas" y "masculinas" a cada sexo. La sociedad elabora las ideas de lo que "deben ser" los hombres y las mujeres, de lo que es "propio" de cada sexo. El género es todo aquel significado que se elabora a partir de la interpretación de la diferencia biológica ${ }^{(22)}$. Como categoría de análisis, el género permite comprender la naturaleza social que adquiere el cuerpo al trascender el mundo natural y arribar a la cultura. En el cuerpo, la diferencia sexual, anatómica y fisiológica existe como base material de las ideas culturales que redefinen al sustrato biológico y lo configuran en cuerpo socializado, en dicha redefinición se emprende una inscripción de qué significa ser hombre o ser mujer. El género, en tanto establece una relación entre las estructuras generales de la sociedad y la estructuración del sujeto individual, es un elemento constitutivo de las relaciones sociales ${ }^{(23)}$. No se puede aludir a un cuerpo que no haya sido interpretado mediante significados ${ }^{(24)}$ cuya dependencia del orden social vigente establecen modalidades hegemónicas sobre cómo comprender y ejercer el género y la sexualidad, la construcción de la identidad de los sujetos está determinada por la cultura de género prevaleciente pero, por otra parte, existen cuerpos que se resisten a la inscripción del género, sea voluntariamente o como inevitabilidad de su propia naturaleza. En la cultura patriarcal, en que la masculinidad adquiere una mayor valoración social que la feminidad, las personas que traspasan los límites del género tienden a ser vistas con desprecio ${ }^{(6)} y$, en ese sentido, el cuerpo de la persona trans es un territorio que se niega a la inscripción de los significados y prácticas que constituyen el género y la orientación sexual, socialmente asignados.

El género no es un depósito estático, se produce performativamente, impuesto por prácticas reguladoras y requiere ejercerse. Es una realización de los significados y prácticas que lo componen, la performatividad no es un acto único, sino una repetición constante que consigue su efecto mediante su naturalización en el cuerpo ${ }^{(24)}$. El género representa una actuación que se asigna con un sistema de reconocimientos y sanciones sociales, no es un atributo preexistente a la socialización ${ }^{(25)}$, es una representación de las exigencias sociales, por ello se considera que el sujeto nunca es dueño de su género pues no retoma el que más le satisface sino el que se ve obligado a "actuar" en función de una normativa genérica.

La psiquiatría y la salud pública se constituyeron como instancias funcionales a la moral burguesa ${ }^{(11)}$ del sexo, el género y la sexualidad, anclaron su saber y prácticas concibiendo a la sociedad como organizada en una figura de la alianza familiar ${ }^{(11)}$ de base heterosexual y reproductiva, a partir de la cual elaboraron estructuras dicotómicas subsecuentes como normal/anormal, sano/enfermo, estableciendo categorías nosológicas impuestas como referentes identitarios, de tal manera que la sexualidad es producto de múltiples intervenciones sociales. Este planteamiento permite reconocer el impacto de la reglamentación sexual que valora positiva o negativamente las actividades corporales que ejercen los individuos ${ }^{(26)}$.

La medicina científica jugó un papel fundamental en la configuración de las sociedades modernas. Su influencia puede analizarse a través de la medicalización, definida como el proceso por el cual la medicina moderna convierte algunos objetos de la realidad en sus objetivos ${ }^{(27)}$, desde su ámbito de intervención. Para algunos de ellos, relacionados con la sexualidad, tuvo que elaborar una justificación ideológica que se dijo científica, para su apropiación, conductas no reproductivas requirieron de construirlas como patologías, atribuyéndole a la medicina la función de intervenir para el control, erradicación o restauración de los cuerpos anómalos $^{(12)}$. Que ciertas conductas se piensen como enfermedades implica que sean explicadas e intervenidas a través de técnicas y concepciones biomédicas caracterizadas por la racionalidad científica moderna ${ }^{(28)}$.

\section{MÉTODO}

Con el propósito de describir los procesos de medicalización en la performatividad de 
género y su relación con la salud de un grupo de mujeres trans de la Ciudad de México, se realizó un estudio cualitativo, observacional y descriptivo que recupera el discurso de su experiencia con la readecuación sexogenérica. Para tal fin, se elaboró una guía de entrevista semiestructurada para que, mediante la evocación retrospectiva de su identidad, las entrevistadas produjeran un discurso reflexivo.

Desde la perspectiva cualitativa, la representatividad de los datos obtenidos radica, no en la cantidad, sino en la procedencia de los informantes considerados claves y en la naturaleza testimonial de la información que provean. Por la estigmatización que caracteriza a la población trans, se aplicó la técnica de bola de nieve, y se adoptó la recomendación metodológica de reclutar informantes a partir de uno que reuniera las características de mayoría de edad, definirse como trans o estar en proceso de adecuación sexogenérica, con disposición de narrar ampliamente su experiencia y ser grabada, y que tuviera conocimiento de otras personas que reunieran los mismos criterios. El primer contacto se realizó mediante un grupo de autoayuda en la Clínica Condesa de la Ciudad de México. La agregación de informantes finalizó cuando los investigadores identificaron suficientes regularidades en sus narrativas.

El trabajo de campo se realizó durante el año 2015 y participaron en el estudio diez mujeres trans, cuyas entrevistas duraron entre 40 minutos a 2 horas cada una. Algunas características sociodemográficas de las entrevistadas se resumen en la Tabla 1.

El proyecto de investigación fue discutido en sus aspectos de diseño y consideraciones éticas por las instancias académicas correspondientes. A cada informante se le dio a conocer el propósito general del estudio, el papel de su participación y se les garantizó la confidencialidad y anonimato en el manejo de los datos, así como el uso exclusivo de su información con fines científicos. También se solicitó su autorización para que las entrevistas fueran audiograbadas. Con lo anterior se elaboró una carta de consentimiento informado que fue firmada por los investigadores y las informantes.

Una vez transcritas, las entrevistas fueron analizadas por fases ${ }^{(29)}$. En una primera fase,

Tabla 1. Características generales de las entrevistadas. Ciudad de México, 2015.

\begin{tabular}{|c|c|c|c|c|}
\hline Id & Edad & Actividad laboral & Nivel de estudios & Situación de pareja \\
\hline 01 & 35 & $\begin{array}{l}\text { Promotora de salud sexual y trabajadora sexual } \\
\text { ocasionalmente }\end{array}$ & Secundaria & Soltera \\
\hline 02 & 18 & Empleada & Secundaria & $\begin{array}{l}\text { Cuenta con pareja varón } \\
\text { heterosexual }\end{array}$ \\
\hline 03 & 50 & Empleada administrativa en institución pública & Posgrado & Soltera \\
\hline 04 & 23 & Obrera & Bachillerato* & Soltera \\
\hline 05 & 31 & $\begin{array}{l}\text { Promotora de salud sexual y trabajadora sexual } \\
\text { ocasionalmente }\end{array}$ & Licenciatura & $\begin{array}{l}\text { Cuenta con pareja varón } \\
\text { heterosexual }\end{array}$ \\
\hline 06 & 60 & Estilista & Primaria incompleta & Soltera \\
\hline 07 & 20 & Obrera & $\begin{array}{l}\text { Bachillerato* } \\
\text { incompleto }\end{array}$ & $\begin{array}{l}\text { En pareja con mujer } \\
\text { heterosexual }\end{array}$ \\
\hline 08 & 48 & Ingeniera y locutora de radio & Licenciatura & Soltera \\
\hline 09 & 26 & Obrera & Secundaria & Soltera \\
\hline 10 & 34 & Estilista & Secundaria & Soltera \\
\hline
\end{tabular}

Fuente: Elaboración propia.

*Bachillerato: es el grado posterior a la educación secundaria y previo a la licenciatura. 
se distinguieron categorías discursivas claves, por la importancia que las propias entrevistadas les dieron a los tópicos previstos en la guía de entrevista o que surgieron como categorías emergentes. En la segunda fase se identificaron las relaciones que las entrevistadas establecieron entre categorías. La tercera fase consistió en identificar regularidades y diferencias testimoniales y distinguir si respondían a una experiencia semejante entre las informantes o a su particular trayectoria de vida. Una vez seleccionados los fragmentos regulares, en la última fase se elaboraron temáticas en función de las asociaciones discursivas definidas en la segunda fase y sobre estas agrupaciones se hizo una interpretación a partir de un marco teórico básico.

\section{RESULTADOS}

\section{El cuerpo y la identidad}

A partir del siglo XIX el cuerpo es abarcado por las ciencias biológicas, cuando la medicina asume también un rasgo heteronormativo al definir como sexualidad "saludable" aquella que posibilita la reproducción, medicalizando el cuerpo y la conducta sexual. En el siglo XX las ciencias sociales comienzan a plantearse teóricamente al cuerpo, enfocándolo como espacio de intervención de la medicina y del orden social vigente ${ }^{(30)}$.

El cuerpo es una dualidad, objeto y sujeto $^{(30)}$ en una unidad que interpreta $y$ siente, en la que el sujeto existe en sí y crea su exterior para reconfigurarse y reconfigurar al otro, lo que da como resultado un cuerpo permanentemente incompleto. El cuerpo es un producto social ${ }^{(31)}$, conjunto de significaciones experimentadas que aloja la salud como una condición saturada de valoraciones sobre lo patológico ${ }^{(32)}$.

Cuando el individuo irrumpe en el mundo simbólico, ya existe una significación previa del ser hombre o mujer a partir de la cual el sujeto construirá su identidad, ser un "verdadero" hombre o una "verdadera" mujer, implica cumplir con lo establecido. En una mirada inicial, el cuerpo trans transgrede el orden por no mostrar correspondencia entre la dicotomía del sistema sexo-género ${ }^{(33)}$ que impone la cultura de género y la supuesta complementariedad biopsíquica entre el cuerpo de un varón y el cuerpo de una mujer que impone la heteronormatividad ${ }^{(17)}$, dicha transgresión parece mayor pues, en apariencia, las mujeres trans "eligen" devaluarse en la escala social al "renunciar" al elevado estándar que significa la masculinidad. La identidad trans se configura en un régimen heteronormativo y conservador que les "ofrece" a las transexuales, un margen binario de opción para la expresión del género por lo que, en general, se esfuerzan en adoptar los rasgos que constituyen los estándares dominantes del género ${ }^{(34)}$.

\section{...no solamente me asumo como mujer, digo que soy mujer, aceptando la incom- prensión, el rechazo, la burla... [03]}

El sujeto significa su cuerpo como espacio de los significados y prácticas que constituyen la cultura dominante y lo moldea.

...Me puse la camiseta de hombre y así viví mucho tiempo [...] uno de mis primos era mujeriego, me quise comportar como él, como mi padre, como mi hermano [...] tener esa máscara... ya no podía con eso, no era yo [...] soy una mujer, ahorita no me veo como tal, pero lo quiero ser, tengo que percibirme físicamente como una mujer [04]

El cuerpo-objeto es plastificación del cuerpo-sujeto, producto de intervenciones biológicas y sociales, capaz de enfrentarse a las estructuras sociales que lo determinan y que aprobarán o rechazarán, lo que lo convierte en un cuerpo expropiado de su vida privada y sometido a la sociedad; producido en la normatividad, que construye tipologías de cuerpos. Las categorías clínicas de la medicina forman parte de estas imposiciones.

...yo no soy una transexual [...] soy una mujer que nació en el cuerpo equivocado. No me identifico como transexual... [09] 
...me identificaba con la palabra transexualidad, me sentía yo transexual porque inicialmente yo decía que era travesti y es que muchas chicas que no tienen información correcta, se identifican de diferentes maneras [01]

El valor que la sociedad le asigna a afectos y emociones que radican en el cuerpo, determina la forma en que el sujeto-cuerpo da trámite a su experiencia y la incorpora, resultando un territorio de sensaciones afectivas valorizadas positiva o negativamente.

...jviví en el cuerpo con que nací durante décadas! pero no odio al hombre que fui, mi pene contribuyó a la existencia de mis hijos [...] y me dio horas de autosatisfacción [...] soy lo que quiero... [03]

...me siento muy bien [...] cambios muy ligeritos me dan mucha emoción [...] ya noto un poco más de cadera, ya creció el busto... [07]

La integración a la sociedad incluye la incorporación de las identidades de género que la estructura social dispone, las emociones responden a esta instauración convirtiéndose en construcciones dotadas de valor subjetivo.

...trasvestirme era sentirme muy a gusto, sentirme lo que yo quería ver: una mujer [...] lo dudaba por miedo a lo que diría mi familia y la sociedad, te da miedo [...] cuando decidí ser transexual dije, voy a romper con todo esto... [01]

El cuerpo concentra transacciones emocionales con las que el sujeto lidia en su entorno. Las afectividades se someten al imperio de las posibilidades ofrecidas con las que la persona trans gestiona su salud.

...a los siete años [...] estaba muy desubicada [...] ¿qué estaba pasando adentro de mi cuerpo, porque yo quería unas cosas y me decían que estaban mal [...] a los 20 fue cuando empecé con el tratamiento y ya tuve muchísima más seguridad [10]

\section{¿Trans-grediendo el género o el género en transición?}

La cultura de género predominante en un periodo histórico determina las interacciones individuales entre varones y mujeres, pero subordina todas las relaciones a su lógica, las instituciones y la subjetividad, ofreciendo las opciones socialmente aceptables para la integración social. El género refleja de forma corporal construcciones sociales que intentan reducir la realidad a una estructura dicotómica, jerarquizada y heterosexual que genera exclusiones.

\begin{abstract}
...ipor qué no me puedo comportar así? [...] era algo que sabía que no podía hacer porque era hombre [...] Mi abuelo decía 'No!, ¡te me comportas como hombre!', inmediatamente capté: o te comportas así o ahí te va el cinturonazo, era una educación con golpes... [04]
\end{abstract}

El género nunca es la fiel traducción de los modelos pretendidos por el orden, la relación entre género y cuerpo es una experiencia $y$, en ese sentido, las identidades sexogenéricas que se distancian de la heteronormatividad, dan cuenta de que el binarismo de género es un artefacto cultural ${ }^{(35)}$. En tanto la vida de las personas trans transita fuera de esta normatividad, la mujer trans es leída por el resto de la sociedad como un fenómeno atípico $^{(36)}$. La persona trans nos demuestra que el género se representa y que el cuerpo aloja esa representación. El género se produce performativamente ${ }^{(37)}$, los roles de género no se corresponden a ninguna base biológica, dependen de las asignaciones sociales, las oposiciones y resistencias que pueden transformarlo, así como de las transacciones afectivas de los individuos. Las oposiciones binarias femenino/masculino, heterosexual/ homosexual que impone la cultura de género se pueden entender también como repetición de actos performativos. 
...empecé a ser más femenina [...] me empecé a depilar, me dejé crecer el cabello... [01]

...en la primaria no tienes idea de cómo me discriminaban [...] se supone que todos deben tener novia, la busqué, era una de mis amigas que me decía 'hay que aparentar' pero no me sentía cómoda. [09]

La incorporación del género requiere del aprendizaje de las prescripciones y proscripciones que integran la normatividad del género y que son impuestas mediante tecnologías disciplinarias que saturan al cuerpo de normas para la "correcta" representación del género a través de la adopción de estereotipos y roles. Los actos performativos expresan el apego a la normativa de género, marcan el cuerpo por la aspiración de ser aceptado o por el temor a la exclusión.

...me vestía con la ropa de mi mamá o de mi hermana, a escondidas... [02]

...cuando no estaba yo travestida, o sea en el papel socialmente aceptable de varón, estaba yo interpretando a un personaje... tenía yo que interpretar a un chico... no me gustaba [08]

En esta performatividad, el sujeto nunca es dueño de su género, pues no retoma el que más le satisface per se, sino que se ve obligado a "actuar" el género que le imponen ${ }^{(37)}$.

...parte de esa feminidad sí resulta conscientemente, performativamente con la forma en que se mueven las princesas de Disney, el manejo de las manos [...] yo como mujer no digo groserías... [03]

...me decían: "caminá como hombre, no como puto" [...] me agredían muy fuerte, entonces yo aparentaba ser hombre [...] jugar fútbol, jugar luchas, boxear, tenía que hacer todo ese tipo de cosas para que no me lastimaran... [01]
En la medicalización, lo catalogado como patológico es acreedor de las intervenciones terapéuticas para la reinserción del sujeto transgresor del orden. En las sociedades modernas, la sexualidad fue articulada ideológicamente al esquema hetero por resultar idónea para la moral burguesa. La persona trans cuestiona la supuesta secuencia "normal" entre sexo, género y heterosexualidad, mostrando la autonomía de estas tres dimensiones, complejizando las transacciones afectivas con las que el sujeto trans debe lidiar para su identidad.

...yo pensaba: "es pasajero, yo soy padre de familia, quiero a mis hijos, quiero a mi esposa, pensaba yo, soy heterosexual" [03]

En la persona trans se multiplican los efectos de mostrar más de un referente identitario que contradice el orden social, ya que no sólo expresa un género que no "corresponde" a su cuerpo, además no se sujeta a la heterosexualidad.

La primera referencia que tuve para mi identificación fue la etiqueta "shemale" (que nace del contexto de la pornografía, de chicas que siguen usando su pene), yo decía: "pues sí 'she' mujer, vengo de 'male': masculino, vengo de ahí. Soy 'shemale'". Pero al poco rato me dijeron no, para nada [...] hoy me asumo como mujer transexual bisexual... [03]

...se lo expliqué pero no lo asimiló de golpe [...] él regresó conmigo, dice que no importa, prefiere una mujer-hombre que un hombre-hombre [...] nos llevamos muy bien [...] hay que dar información sobre lo que es transexual, transgénero y lo que es travesti porque hasta la misma sociedad lo confunde con orientación sexual, porque nos dicen homosexuales, nos dicen putos, nos dicen jotas [01]

...llegué a tener parejas hombres, pero no era lo que yo buscaba [...] en ese momento dudaba porque no sabía lo que era la comunidad trans [...] no se conoce 
lo que es una trans [...] yo pensaba que era hombre, pero gay, o sea llegué a dudar de mi interior [09]

Podemos considerar, entonces, que las mujeres entrevistadas reprodujeron las estructuras de la cultura de género dominante que les impone la necesidad de autodenominarse bajo las categorías preestablecidas en el sistema sexogénero de base binaria.

\section{Medicalización, ¿imposición o recurso?}

Como práctica social, la medicina puede ser considerada un sistema de producción de cuerpos $^{(35)}$ a partir de una estructuración heterosexual de la sociedad. La medicalización de la sexualidad y la consecuente patologización de las expresiones no heterosexuales, incluye la asignación social a la medicina para ejercer los procedimientos para "reparar" los daños o disminuir los riesgos a la salud con que han sido significadas las prácticas no reproductivas. En esa perspectiva, toda anomalía sexual "requiere" de procesos terapéuticos para ajustar el cuerpo individual al cuerpo social, "ajustando" la identidad sexual a la de género. Si bien, en un primer momento, la persona trans es construida como enferma, posteriormente, la misma medicina le ofrece la posibilidad de materializar la integración de su identidad mediante la intervención psicoterapéutica y quirúrgica.

...para mí una operación no quiere decir que ya voy a ser mujer, mi sentir es lo que realmente me hace mujer [01]

Todavía no voy con el endocrinólogo, nomás fui con la psicóloga [...] me ha ayudado bastante, al menos para empezar con el ámbito psicológico que es importante para seguir después con las hormonas... [04]

El saber médico amplía sus métodos de intervención haciendo concebir como necesarios sus procedimientos de corrección de la anomalía, estratificando sus niveles, realizando pruebas clasificatorias y aprobatorias para realizar algún procedimiento sobre el cuerpo, haciendo de la medicalización un recurso considerado "necesario" y hasta "obligatorio".

...Me dijeron que me iban a hacer unos estudios, un examen psicológico y un examen médico. De ahí iban a procesar para ver con qué cantidad de hormonas iban a comenzar conmigo [...] Tienen que hacer un examen psicológico y un examen médico. El psicológico básicamente es para detectar que realmente haya una disforia de género y para asegurarse que la persona no se vaya a arrepentir [...] Ya cumplí un año que se supone que es el tiempo estándar para empezar a operarme, estoy viendo cómo costear la primera operación, sería facial [...] después de eso, tendría que costear la vaginoplastía. [02]

...quiero ir a terapia porque realmente quiero hacer bien mi transición [...] me mandaron con el terapeuta [...] necesitas tener el aval del terapeuta para el tratamiento hormonal [...] el terapeuta decide que es lo que necesitas, qué es lo que quieres... [08]

Desde una visión mecanicista, el cuerpo es una máquina, susceptible de descomposturas y la medicina debe ser capaz de restablecer el funcionamiento mediante la sustitución de piezas o refacciones. El proceso de reasignación sexogenérica ejemplifica estos rasgos de la medicalización: sustituye hormonas, amputa fragmentos, los modifica, agrega nuevos, corrobora el "ajuste" psíquico y todos estos procesos pueden resolver la relación previamente patologizada entre el cuerpo y la identidad sexual de la persona trans.

...me decían: "estás enfermo, es una enfermedad" [...] mi mamá decía que era el demonio, que necesitaba una limpia [09]

...mi amiga me sugirió que deberíamos buscar un psicólogo [...] para ver si había 
algo que pudieran arreglar o para que me pudiera integrar a la sociedad... [08]

La falta de conocimiento sobre los procesos socioculturales, políticos y económicos ${ }^{(38)}$ en los que ocurre la salud y la enfermedad impiden comprender ciertos fenómenos y despierta un impulso por establecer una serie de diagnósticos encaminados a patologizar aquello que no comprendemos bajo el esquema heterocentrista que frecuentemente es reproducido y legitimado por los propios pacientes.

Sí, quería ir al psicólogo porque yo veía que muchas transexuales se convierten en mujer y salen con hombres. Y yo decía: "no, es que yo me quiero convertir en mujer y salir con mujeres" [...] yo decía: "entonces sí estoy loco ¿¿Cómo voy a querer ser mujer y salir con mujeres?!" [07]

También pueden observarse posiciones contestatarias a la medicalización entre las mismas personas trans que, en algunos casos, consideran que no es necesaria la intervención de la biomedicina como legitimador de sus identidades.

...la enfermedad no es ser transgénero o transexual, jes la ignorancia! hay psicólogos que no saben qué es transexual, saben qué es homosexual pero nada más. Muchos psicoanalistas y psiquiatras se casan con la idea de que solo la homosexualidad no es una enfermedad, ique la transexualidad síl, o la ven como una parte más de la homosexualidad... [08]

...no estoy loca y creo que las demás no estamos locas, simplemente es un sentir [...] no creo que sea un trastorno [01]

¡Claro que no es una enfermedad! [...] es decisión de cada persona, y mi decisión fue verme como mujer [...] cuando tú decides qué es lo que quieres ser en tu vida no es enfermedad [10] ...no cumplir con los estereotipos de ser hombre o ser mujer me llevó a pensar que estaba enferma, me sentía sucia por ser algo que para los demás no era normal. No me gusta la palabra "normal" pero hay que enfatizarla porque para ellos, cuando no cumples con los estereotipos, no eres normal... [05]

La automedicación expresa la difusión de la idea clínica de "corregir" el cuerpo, el proceso que emprende la persona trans para integrar su identidad, incluye prácticas que implican riesgos a la salud, estos son resignificados, de modo que resultan menores frente al imperativo de los estándares sociales del género.

...está el riesgo de la medicina privada "mercenaria" que no es toda, pero en situaciones como la nuestra ¿quién nos defiende?, una intervención en la medicina privada no se registra como reasignación de sexo sino como cirugía "estética", entonces sí hay muchos problemas [03]

Una amiga inyectaba aceites en el cuerpo, ella empezó a modificarme [...] sentía que estaba logrando el cuerpo que quería [...] me dijo: “¿no te gustaría que te pusiera nalgas? para que las tengas más ricas, a los hombres les gusta que te veas más femenina"... me las puso [...] hoy tengo complicaciones en mis glúteos [...] son dolores muy fuertes, he conocido amigas que se han muerto, el líquido se sube a los pulmones y les da trombosis pulmonar, a los riñones, a los testículos, se les baja a los pies, se les hace un pie de elefante [...] he visto muchos casos de amigas que les explota el aceite y les deja llagas... [01]

\section{Violencia y cotidianidad trans}

La violencia contra las personas trans se inicia desde edades tempranas ${ }^{(39)}$, y la podemos considerar como un instrumento de 
aprendizaje de la normatividad sexual, las modalidades narradas incluyeron violencia física, psíquica y sexual.

...me ponía vestidos de mis hermanas, me pegaba mi hermano, mi papá o mi mamá [...] con toda esa violencia te das cuenta que estás atrapada en un cuerpo que no corresponde a tu identidad [...] tenía un chingo de miedo [...] en la secundaria llegué a tener mucha violencia por mi identidad. [...] los compañeros me golpeaban... [05]

Mis primos [...] me obligaban a que yo les tocara sus partes, varias veces intentaron violarme [...] Hubo golpes, mis tíos me pegaban [...] lo único que escuchaba era: "mierda, puto, maricón, basura, demonio" [...] ese señor... me perseguía, me pateaba, escupía, me decía "no vales nada", intentó abusar de mí [09]

El estigma de la patologización forma parte de la determinación social de las condiciones de salud de la población trans ${ }^{(6)}$. La discriminación como expresión concreta de la estigmatización y la violencia, influye en los servicios de salud que reciben las mujeres trans debido a la falta de capacitación y sensibilización de los profesionales de la salud.

...somos excluidas de todo, no tenemos un trabajo digno, tengo muchas amigas que son licenciadas y no pueden ejercer por su identidad de género [...] una vez me puse muy mal y no me quisieron aceptar en un hospital, me tuvieron que llevar a otro [...] En el mismo sector salud, no me gusta que me hablen con mi nombre de hombre porque yo no soy hombre... [01]

...me han negado el servicio de salud por ser trans [...] seguimos viviendo exclusión, discriminación, estigma y violencia [...] hay un centro trans donde ya hay supervisión médica pero el personal no está sensibilizado, te trata mal, te discrimina [05]
La discriminación puede ser doble y provenir de otros grupos también históricamente excluidos.

...empecé a descubrir que los hombres que se acuestan con otros hombres, discriminan a las travestis o a las transgénero, dicen: "es una vestida". Si a ellos mismos les dicen putos ¿por qué ellos discriminan a una mujer trans? [07]

La experiencia de la violencia impacta negativamente en la salud mental. La asociación entre exclusión y sufrimiento psíquico está mediada por la autovaloración negativa y el aislamiento social.

...en la escuela, sí sufrí bastante bullying [...] me juntaba con muy poca gente [...] era muy aislada [02]

La violencia no es solo una noción intermedia entre la imposición de la heteronormatividad y los daños a la salud o de un recurso para el sostenimiento del orden heterosexual, se trata de una constante en la vida cotidiana de las personas $\operatorname{trans}^{(39)}$ que redefine sus posibilidades de bienestar y las hace extremadamente vulnerables.

\section{Daños a la salud}

Como resultado de la violencia, las entrevistadas dieron cuenta de un conjunto de riesgos y daños a la salud. Las particularidades de este patrón o perfil están vinculadas a la patologización y a la readecuación, ya sea por introyección del rechazo social como por las intervenciones médicas o las que realiza la misma persona trans, resultados que coinciden con otros reportes ${ }^{(6)}$. Los daños más mencionados fueron a la salud mental, principalmente con síntomas relacionados a depresión, ansiedad y conducta suicida.

[Sentía] odio, ataques de depresión [...] bastante negación, dificultad para poderme integrar en la sociedad [...] 
sigo siendo bastante antisocial [...] tengo mucho odio hacia mí misma y más que nada hacia lo que fui [...] estuve 22 años viviendo una mentira [...] en un momento de desesperación cuando ya no podía más, hace un año, tenía $22 .$. [silencio] traté de suicidarme [02]

...mucha tristeza, Iloraba mucho [...] quería irme o morirme [...] me sentía humillada [...] denigrada... [01]

...toda la sociedad me señalaba, me discriminaba, me escupía... jtenía 5 años y ya me quería suicidar!, no soportaba tanto rechazo, tanta humillación, tantos golpes que varias veces intenté suicidarme [...] sentía asco hacia mí misma, miedo, impotencia [...] todos los días le decía a Dios: “¿por qué?, ¿por qué no me hiciste varón o mujer? y no estar en esta situación" [09]

...las hormonas tienen que ir de la mano con la terapia porque hacen una serie de cambios físicos y psicológicos, puede haber desde depresión que es común, ansiedad, ataques de pánico [08]

El acceso a la salud es una problemática grave en esta población ${ }^{(40)}$, en la readecuación sexogenérica, las mujeres trans tienen mayor riesgo de cáncer de mama, heridas, necesidad de reducir implantes mamarios, edemas crónicos e infecciones recurrentes ${ }^{(41)}$ y las posibilidades de acceso a la readecuación están determinadas por condiciones económicas. Las personas trans pueden verse obligadas a abandonar la escuela o el trabajo por la violencia, y la baja escolaridad impone un menor acceso a terapéuticas seguras. Las hormonas, los implantes, y su colocación son finalmente mercancías cuya calidad hace variar su seguridad; muchas intervenciones son Ilevadas a cabo con materiales y en lugares que implican riesgos. Los efectos negativos de las hormonas autoadministradas, las inyecciones de relleno en tejidos blandos y otros tipos de modificaciones $^{(6)}$ forman parte de los principales daños a la salud que expresaron las entrevistadas. ...muchas amigas inyectan, pero es riesgoso porque luego mezclan aceite mineral, biopolímero [...] y aceite de comer [...] yo tengo estos pequeños problemas, pero he visto a muchas que después tienen que "rasparles" [...] yo hacía mezclas de todas las hormonas, sabiendo que corría mucho riesgo... [01]

...a una amiga no le realizaron bien la cirugía [...] la herida se le abría, un día se le salió toda la prótesis [...] tengo varias amigas que les han causado abscesos, tejido muerto [05]

...saliendo del trabajo me iba a trabajar a otro lado [...] para ahorrar para mi tratamiento hormonal porque salía en un ojo de la cara [...] conozco una chica trans que todo su tratamiento es automedicación, ella nada más lleva dos tipos de hormonas y se lo aplica cada ocho días, gracias a Dios no ha tenido complicaciones, pero se ha aplicado aceite de avión en los glúteos... [09]

...no todas tienen la posibilidad de pagar un médico, no hay posibilidad de tratamiento hormonal aunque seas derechohabiente del sistema público [...] si en Ciudad de México es difícil conseguir terapeutas, en otros lugares es peor [...] el tratamiento hormonal gratuito solamente se da en Clínica Condesa, es necesario hacerlo federal para que las chicas que viven en los estados no tengan que recurrir a inyectarse aceites minerales, de cocina, incluso a veces hasta de motor para tener senos [...] porque esto las lleva a la muerte en algunos casos [08]

\section{CONCLUSIONES}

La impronta de la identidad trans se inserta en una paradoja de la medicalización, por un lado, es patologizada, lo cual produce rechazo social y daños a la salud; por otro 
lado, la medicina ofrece las posibilidades objetivas para la readecuación sexogenérica como una expresión de la performatividad del género. La patologización influye radicalmente en la identidad trans, determina mayores problemas de salud y, al mismo tiempo, el acceso a la readecuación en las condiciones más seguras las obliga a declararse enfermas. En ese sentido, la medicina puede ser vista como la que enferma y cura.

La heteronormatividad pretende reproducir dos únicas identidades de género y producir prototipos y cuerpos disciplinados para reivindicar la articulación ideológica entre sexo, género y heterosexualidad como modo de vida "correcto". La experiencia de las entrevistadas estuvo permanentemente atravesada por afectos contradictorios sobre su identidad y el temor permanente a la sanción. El orden social busca inscribir homogéneamente en los cuerpos de todas las personas los estereotipos y roles que constituyen la cultura dominante de género, disciplinándolos para representarla mediante la práctica de violencia física, psicológica y sexual que produce en personas no heterosexuales, importantes daños a la salud mental. En el caso de las mujeres trans la violencia experimentada fue predominantemente psicológica, física y sexual, en el ámbito privado, ejercida por conocidos $y$, con frecuencia, por familiares, y produjo depresión, ansiedad y conducta suicida.

La medicalización impone a la persona trans incorporarse, mediante readecuación sexogenérica, a la dicotomía hombre-mujer y masculino-femenino que son, al mismo tiempo, las estructuras en las que se origina su rechazo social. En dicho proceso, las trans reafirman los atributos físicos que más se exigen y valoran en las mujeres. Esta performance las hace vulnerables a otros daños a la salud: heridas, infecciones, edemas y otros ${ }^{(41)}$. Al optar por este camino, ponen en evidencia la fuerza de la cultura sobre la biología, reafirmando que las exigencias culturales en función del género, se expresan en la salud.

Las experiencias compartidas por las mujeres trans de este estudio demuestran la autonomía entre sexo, género y sexualidad que se opone a la unidireccionalidad que propone la norma social prevaleciente basada en la reproducción biológica. Algunas mujeres trans muestran una orientación homosexual del deseo. El cuerpo trans opera como espacio en el que confluye la imposición de la norma y su disidencia, haciéndolo objeto de discriminación.

Es urgente combatir la discriminación a las personas trans, e implementar la perspectiva de género y diversidad sexual en los servicios médicos y en la formación de profesionales de la salud. La tecnología médica que se ha desarrollado para la readecuación sexogenérica, entendida como el conjunto de prácticas de modificación corporal de diferente tipo y alcance ${ }^{(35)}$, debe avanzar en materia de intervenciones farmacológicas y quirúrgicas más seguras, especialmente, porque implican para las informantes una mayor armonía entre su cuerpo y su identidad, y muestran sentimientos de bienestar que aumentan la confianza y seguridad en sí mismas. Las mujeres trans buscan la reasignación no solo para la integración de su identidad sino con finalidades más prácticas: "sentirse mejor", expresar lo que "verdaderamente son". Avanzar hacia la despatologización de su identidad y despatologizar también su acceso a los servicios médicos, son los principales retos a enfrentar para la realización de la salud en las mujeres trans.

El presente estudio aporta datos de primera fuente que contribuyen a la caracterización de los procesos de determinación social de las condiciones de salud que muestran las mujeres trans. Los testimonios permiten establecer, con mayor claridad, la asociación entre el rechazo social a la transexualidad y su impacto en la salud. También se abren interrogantes relacionados con la interacción de otras adscripciones culturales como la clase social, etnicidad o migración y sus posibles efectos sinérgicos en el perfil epidemiológico, así como la necesidad de dar seguimiento a las intervenciones a favor del reconocimiento de los derechos de las personas trans en sus condiciones de vida, tanto en términos de avances como incluso, de retrocesos o amenazas. 


\section{REFERENCIAS BIBLIOGRÁFICAS}

1. Consejo Nacional para Prevenir la Discriminación. Encuesta Nacional sobre Discriminación en México 2010. México: CONAPRED; 2011.

2. Cutuli M, Farji A. Mapeando estrategias: iniciativas, oportunidades y dificultades en la implementación de la Ley de Identidad de Género en el ámbito sanitario. XII Jornadas Nacionales de Debate Interdisciplinario en Salud y Población; 3 al 5 de agosto 2016; Buenos Aires, Argentina.

3. TGEU Transgender Europe. TDoR 2016 press release [Internet]. c2016 [citado 21 nov 2016]. Disponible en: https://goo.gl/GEysGu.

4. Organización Panamericana de la Salud, Organización Mundial de la Salud. Clasificación internacional de enfermedades y problemas relacionados con la salud, Décima Revisión. Washington DC: OPS, OMS; 1995.

5. American Psychiatric Association. Diagnostic and statistical manual of mental disorders. 5th ed. Washington DC: London: APA; 2013.

6. Organización Panamericana de la Salud. Por la salud de las personas trans: Elementos para el desarrollo de la atención integral de personas trans y sus comunidades en Latinoamérica y el Caribe [Internet]. [2012?] [citado 17 may 2017]. Disponible en: https://goo.gl/2x6wHr.

7. Balsam KF, Beachaine TP, Mickey RM, Rothblum ED. Mental health of lesbian, gay and heterosexual aiblings: effects of gender, sexual orientation and family. Journal of Abnormal Psychology. 2005;114(3):471-6.

8. Granados JA, Delgado G. Homofobia y salud. Salud Problema. 2006;11(20):35-51.

9. Meyer IH. Prejudice, social stress and mental health in lesbian, gay and bisexual populations: conceptual issues and research evidence. Psychological Bulletin. 2003;129(5):674-697.

10. Jorm AF, Korten AE, Rodgers B, Jacomb PA, Christensen $H$. Sexual orientation and mental health: results from a community survey of young and middle-aged adults. The British Journal of Psychiatry. 2002;180:423-427.

11. Foucault M. Historia de la sexualidad. Buenos Aires: Siglo XXI Editores; 2008.

12. Foucault M. Historia de la medicalización. Educación Médica y Salud. 1977;11(1):3-25.
13. Courtwright A. Justice, stigma and the new epidemiology of health disparities. Bioethics. 2009;23(2):90-96.

14. Granados JA. Medicina y homosexualidad: Prácticas sociales en tensión. Cuicuilco. 2006;13(36): 293-319.

15. Lamas M. Diferencias de sexo, género y diferencia sexual. Cuicuilco. 2000;7(18):95-118.

16. Lamas M. La antropología feminista y la categoría de género. Nueva Antropología. 1986;8(30):173-198.

17. Wittig M. El pensamiento heterosexual y otros ensayos. Barcelona: Egales; 2006.

18. Cutuli MS. Etnografiando travestis: preguntas, tensiones y aprendizajes sobre el "estar ahí". Sexualidad, Salud y Sociedad. 2013;(13):99-112.

19. Granados JA, Hernández PA, Olvera OA. Mujeres trans: medicalización y proceso de adecuación sexo-genérica. Salud Problema. 2016;10(2):10-29.

20. Godina C. El cuerpo vivido. México: BUAP; 2003.

21. Bourdieu P. El sentido práctico. Buenos Aires: Siglo Veintiuno Editores; 1991.

22. Lamas M. Cuerpo: diferencia sexual y género. México DF: Taurus; 2002.

23. Scott J. El género: una categoría útil para el análisis histórico. En: Lamas $M$, coord. El género: la construcción cultural de la diferencia sexual. México DF: UNAM, PUEG; 1996. p. 265-302.

24. Butler J. El género en disputa: el feminismo y la subversión de la identidad. México: Paidós; 2001.

25. Navarro P. Del texto al sexo: Judith Butler y la performatividad. Barcelona: Eagles Editorial; 2008.

26. Foucault M. La vida de los hombres infames: Ensayos sobre desviación y dominación. Buenos Aires: Altamira; 1996.

27. Foucault M. Medicina e historia: el pensamiento de Michel Foucault. Washington DC: OPS; 1978.

28. Menéndez E. Morir de alcohol: Saber y hegemonía médica. México DF: Alianza Editorial Mexicana, CONACULTA; 1990.

29. Amezcua M, Gálvez A. Los modos de análisis en investigación cualitativa en salud: perspectiva crítica y reflexiones en voz alta. Revista Especializada Salud Pública. 2002;5(76):423-436. 
30. Merleau-Ponty M. Fenomenología de la percepción. Barcelona: Península; 1975.

31. Bourdieu P. La dominación masculina. Barcelona: Anagrama; 2000.

32. Canguilhem G. Lo normal y lo patológico. México: Siglo Veintiuno Editores; 1978.

33. Ferro C. Primeros pasos en la teoría sexogénero. Costa Rica: Instituto de Estudios de la Mujer, Universidad Nacional de Costa Rica; 1994.

34. Lealah P, Silva A, Sevelius J, Salazar X. [Internet]. 'You should build yourself up You should build asas a whole product': Transgender female identity in Lima, Perú. Global Public Health. 2016;11(7-8):981993. doi: 10.1080/17441692.2016.1167932.

35. Farji A. Las tecnologías del cuerpo en el debate público: Análisis del debate parlamentario de la Ley de Identidad de Género argentina. Sexualidad, Salud y Sociedad. 2014;(16):50-72.

36. Farji A. La identidad de género como derecho humano: Análisis del tránsito de un concepto en los discursos del Estado de la Ciudad de Buenos
Aires (período 2003-2010). Revista Punto Género. 2013;(3):123-145.

37. Butler J. El género en disputa: El feminismo y la subversión de la identidad. México: Paidós; 2001.

38. Menéndez E. Modelos de atención de los padecimientos: de exclusiones teóricas y articulaciones prácticas. Ciencia \& Saúde Coletiva. 2003;8(1):185-207.

39. Stotzer RL. Violence against transgender people: a review of United States data. Aggression and Violent Behavior. 2009;14(3):170-179.

40. Cutuli MS. Etnografía de las prácticas organizativas sociales y políticas de una organización de personas trans del Área Metropolitana de Buenos Aires. IX Congreso Argentino de Antropología Social; Facultad de Humanidades y Ciencias Sociales, Universidad Nacional de Misiones, Posadas; 2008.

41. Becerra A. Transexualidad: La búsqueda de una identidad. Madrid: Ediciones Díaz Santos; 2003.

\section{FORMA DE CITAR}

Granados Cosme JA, Hernández Ramírez PA, Olvera Muñoz OA. Performatividad del género, medicalización y salud en mujeres transexuales en Ciudad de México. Salud Colectiva. 2017;13(4):633-646. doi: 10.18294/sc.2017.1363

Recibido: 27 de marzo de 2017 | Versión final: 26 de mayo de 2017 | Aprobado: 3 de agosto de 2017

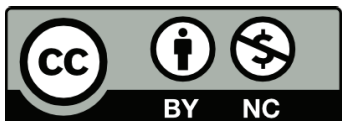

Este obra está bajo una licencia de Creative Commons Reconocimiento-NoComercial 4.0 Internacional. Reconocimiento - Permite copiar, distribuir y comunicar públicamente la obra. A cambio, se debe reconocer y citar al autor original. No Comercial — Esta obra no puede ser utilizada con finalidades comerciales, a menos que se obtenga el permiso. 